\title{
A proposta de cotas e ações afirmativas do Programa de Pós- Graduação em Antropologia Social da Universidade de São Paulo: do tédio à melodia
}

\author{
L Ana Claudia Marques \\ Universidade de São Paulo, São Paulo, São Paulo, Brasil \\ Ana Letícia DE FIORI \\ Universidade de São Paulo, São Paulo, São Paulo, Brasil \\ Cibele Barbalho Assênsio \\ Universidade de São Paulo, São Paulo, São Paulo, Brasil \\ FABIANA DE ANDRADE \\ Universidade de São Paulo, São Paulo, São Paulo, Brasil \\ Jacqueline Moraes TeiXeira \\ Universidade de São Paulo, São Paulo, São Paulo, Brasil \\ Letizia Patriarca \\ Universidade de São Paulo, São Paulo, São Paulo, Brasil \\ TALITA LAZARIN DAL' Bó \\ Universidade de São Paulo, São Paulo, São Paulo, Brasil
}

DOI 10.11606/issn.2316-9133.v25i25p46-55

Desde outubro de 2013, estudantes e professores do Programa de Pós-Graduação do Departamento de Antropologia da Universidade de São Paulo (PPGAS/USP) vêm se mobilizando com o objetivo de implementar ações afirmativas para ingresso em seus cursos de mestrado e doutorado. Nosso intuito neste texto é apresentar a proposta da Comissão Permanente de Ações Afirmativas (CPAA) do PPGAS/USP, ${ }^{1}$ cuja elaboração foi respaldada e inspirada por outras experiências de programas de pós-graduação em universidades públicas brasi-

\footnotetext{
${ }^{1}$ A Comissão Permanente de Ações Afirmativas do PPGAS/USP foi criada em novembro de 2013, sendo composta por estudantes, docentes e funcionários. São elas: Ana Cláudia Rocha Duarte Marques, Ana Letícia de Fiori, Andreia de Moraes Cavalheiro, Cibele Barbalho Assênsio, Fabiana de Andrade, Helena de Morais Manfrinato, Jacqueline Moraes Teixeira, Letizia Patriarca, Luiza Ferreira Lima, Marcio Ferreira da Silva, Marina Vanzolini Figueiredo, Talita Lazarin Dal’ Bó, Vagner Gonçalves da Silva, Yara de Cássia Alves.
} 
leiras, as quais, felizmente, já obtiveram êxito na implementação de políticas afirmativas. ${ }^{2}$ Nas linhas que se seguem, abordaremos, em um primeiro momento, o tema das ações afirmativas em referência a um contexto nacional mais amplo e à USP em particular, para em seguida apresentarmos nossa proposta e descrevermos o longo e intenso processo de nossa mobilização com vistas à sua elaboração e defesa, em diferentes fóruns e etapas dessa jornada, que culminou com sua aprovação, em 2017, e sua inserção no edital de seleção desse ano. Nessa jornada de quatro anos, conquistamos não somente cotas para negras/os e pessoas com deficiência, como também três vagas para indígenas.

É importante ressaltar que coletivos presentes na Universidade de São Paulo deram início muito antes de nós à discussão acerca da necessidade de se implementar ações afirmativas, tais como cotas, em nossa universidade. A esse respeito cabe destacar a importância e o protagonismo do Núcleo de Consciência Negra (NCN), que passou a discutir cotas e a pautar a necessidade política de sua implementação desde o final da década de 1980 e, mais recentemente, da Frente Pró-Cotas, atuante na Universidade desde 2005. Implantar ou não alguma tecnologia política para ações afirmativas na USP tornou-se uma questão para os fóruns centrais da Universidade, em resposta à expansão de modificações nas formas de ingresso no ensino superior público, ${ }^{3}$ em instituições federais e estaduais. Porém, a adoção de um sistema de cotas, conforme pleiteiam aqueles coletivos, tem sido sistematicamente evitada. Em 2006, a USP optou por manter seu sistema convencional de ingresso, o vestibular promovido pela Fuvest, elaborando como política de ação afirmativa o Inclusp (Programa de Inclusão Social), cujo objetivo é adicionar um bônus de $15 \%$ da nota da primeira fase do processo seletivo para pessoas que cursaram o ensino médio em escolas públicas. Em 2011 foi criado o Pasusp, que condiciona uma pequena pontuação adicional a candidatas e candidatos egressos de escolas públicas que estão prestando o vestibular pela segunda ou terceira vez, concedendo-lhes $20 \%$ de bônus. Um critério adicional de bônus dirigido especificamente a pessoas autodeclaradas

\footnotetext{
${ }^{2}$ Como no PPGAS/Ufam, pioneiro na implementação de reserva de vagas para candidatos indígenas desde 2011 e, mais recentemente, em 2016, também para candidatos autodeclarados pretos e pardos; no PPGA/UFPA, que em 2012 iniciou uma proposta de vagas especiais, reservando vagas para pessoas pretas, pessoas com deficiência, pessoas indígenas e servidores da instituição; no PPGAS/MN/UFRJ, que nesse mesmo ano de 2012 aprovou ações afirmativas para candidatos indígenas e candidatos negros; no PPGAS/UFSC, que em 2013 aprovou a implementação de duas vagas suplementares para candidatos autodeclarados indígenas e negros; e no PPGAS/UNB, que em 2015 implementou reserva de vagas para candidatos autoidentificados negros e a destinação de vagas para candidatos autodeclarados indígenas.

${ }^{3}$ Exemplos dessas modificações são: a ampliação do Enem (Exame Nacional do Ensino Médio), que passou a substituir os tradicionais vestibulares para o ingresso nas universidades federais (a partir de 2009) e a criação do Sisu (Sistema de Seleção Unificada), que consiste no oferecimento de vagas considerando a média obtida no Enem (a partir de 2010).
} 
pretas, pardas e indígenas foi implementado a partir de 2013, atribuindo 5\% a mais na pontuação da primeira fase do vestibular.

Em agosto de 2012 foi promulgada pela presidenta Dilma Rousseff a Lei Federal $12.711{ }^{4}$ conhecida como Lei de Cotas, que condiciona instituições de ensino superior federais a reservarem $50 \%$ de suas vagas em cursos de graduação para estudantes egressos de escolas públicas, sendo 25\% dessas mesmas vagas destinadas a estudantes autodeclarados PPIs ${ }^{5}$ (pretos, pardos e indígenas). Em decorrência da lei, o governo do estado de São Paulo apresentou como novo projeto de política inclusiva para as instituições estaduais de ensino superior o Pimesp (Programa de Inclusão por Mérito no Ensino Superior Público Paulista), que insistia na expansão dos mecanismos de acesso através de bonificação para egressos de escolas públicas e PPIs, propondo também um sistema de ensino preparatório à distância como pré-requisito para concorrer às vagas nos cursos de graduação.

Na Faculdade de Filosofia, Letras e Ciências Humanas da USP (FFLCH), foi criada em 2012 uma comissão ad hoc formada por docentes com o propósito de qualificar e situar um posicionamento institucional da unidade frente ao Pimesp. A comissão levantou e sistematizou dados de ingresso na USP que revelaram a pouca eficácia das políticas de bônus até então adotadas nesta universidade. Tais políticas, em pouco mais de uma década de execução, não foram capazes de modificar o perfil de ingressantes no vestibular, majoritariamente composto por pessoas brancas oriundas da rede particular de ensino. Por outro lado, a porcentagem estabelecida pela Lei de Cotas de 2012 considera como princípio para a reserva de vagas a representatividade populacional étnica em cada estado e, seguindo esse mesmo princípio, as instituições paulistas de ensino superior precisariam atingir a porcentagem de 35\% de matriculados autodeclarados PPIs até o ano de 2016. No entanto, segundo dados da própria USP, das 10.733 vagas oferecidas em 2012, apenas 793 foram ocupadas por pessoas autodeclaradas PPIs, o que equivale a apenas $7 \%$ do total de suas vagas. ${ }^{6}$ Como resultado de um conjunto de manifestações que apresentaram posições institucionais contrárias a essa nova proposta, bem como da recepção pública negativa por parte da comunidade acadêmica - movimentos estudantis e organizações

\footnotetext{
${ }^{4}$ A Lei Federal no 13.409, de 28 de dezembro de 2016, alterou esse texto legislativo, passando a contemplar também pessoas com deficiência entre os segmentos para os quais as vagas devem ser reservadas.

${ }^{5}$ Trata-se de uma categoria aplicada pelo sistema classificatório populacional do IBGE e empregada pela Lei 12.711/2012.

${ }^{6}$ Dados disponíveis em: VOGT, Carlos. O que é o Pimesp? Disponível em: <http://www.iri. usp.br/documentos/acoes_afirmativas_pimesp.pdf>. Acesso em: 31 jan. 2017.
} 
especializadas no assunto, como o Núcleo de Consciência Negra -, o Pimesp não foi implementado. E, no entanto, outras medidas de ações afirmativas mais consistentes tampouco foram programadas.

Somado a esse contexto, em 2013 instaurou-se uma greve na USP cuja pauta questionava prioritariamente as engessadas - senão inconstitucionais - estruturas de poder desta universidade, que corroboram com os obstáculos ao acesso e produção de conhecimento por parte de segmentos historicamente excluídos de seus laboratórios, salas de aula, bibliotecas, museus etc., inclusive por meio da obstrução a políticas consistentes de inclusão social. Nesse cenário, pensar uma proposta de ação afirmativa para a pós-graduação se configurou como uma ação tão desejável quanto desafiadora. Estudantes e professores do PPGAS propuseram enfrentar e combater as reticências que prevalecem até hoje na Universidade de São Paulo, motivadas por duas principais críticas à implementação de cotas: primeiramente, ao seu possível impacto na qualidade dos cursos, que poderiam arregimentar alunos "não tão bem preparados"; e, em segundo lugar, à sua "inconstitucionalidade", por tratar de forma diferenciada, num processo de concorrência universal, candidatos com perfis desiguais. Recentemente, uma terceira objeção tem se repetido, acerca da viabilidade de políticas de ação afirmativa em um quadro de crise financeira da universidade e do financiamento do ensino superior brasileiro nos moldes atuais.

Contudo, essas três objeções se mostraram infundadas. A política de cotas, aplicada inicialmente nos cursos de graduação de inúmeras universidades brasileiras, vem recebendo avaliações positivas em relação a critérios como desempenho escolar e taxa de permanência dos cotistas. ${ }^{7}$ Em função disso, também no âmbito da pós-graduação tem crescido o número de programas que vêm adotando essa política, visando, entre outras coisas, a reversão do apagamento histórico de intelectuais não brancos no pensamento social brasileiro, o aumento da diversidade regional, institucional e geográfica nos institutos, faculdades e centros de pesquisa, a multiplicação de repertórios conceituais, cânones bibliográficos e metodologias de pesquisa. $\mathrm{O}$ impacto social e acadêmico dessas experiências tem justificado o apoio orçamentário das universidades que, cabe frisar, é relativamente modesto comparado a outras áreas de investimento com resultados muito menos visíveis. E, após o pronunciamento favorável do Supremo Tribunal Federal à constitucionalidade da adoção de políticas de cotas nas universidades brasileiras, ocorrido em 2012, os empecilhos legais supostamente atribuídos à implementação das cotas no ensino superior caíram definitivamente por terra. Soma-se a tudo isso o fato de que foi publicada pelo Ministério da

${ }^{7}$ Ver, por exemplo, a publicação da UNB intitulada "Análise do sistema de cotas para negros da Universidade de Brasília (2004-2013)”. Disponível em: <http://unb2.unb.br/administracao/ decanatos/deg/downloads/index/realtorio_sistema_cotas.pdf>. Acesso em: 31 jan. 2017. 
Educação (MEC) a Portaria Normativa no 13, de 11 de maio de 2016, que dispõe sobre a indução de ações afirmativas na pós-graduação.

No contexto dessa ampla discussão e de suas reverberações particulares na USP, e considerando a relativa autonomia que os programas de pós-graduação possuem nesta universidade para formulação de seus editais de seleção, elaboramos uma proposta de política de cotas no PPGAS. Após examinarmos diferentes modalidades de ações afirmativas e discutirmos suas especificidades, consideramos que duas delas correspondem às formas mais adequadas de acesso por parte dos integrantes dos segmentos sociais inicialmente contemplados por elas: reserva de vagas para pretos e pardos e pessoas com deficiência; e criação de vagas para indígenas. Nessa decisão prevaleceu a ponderação de que um processo seletivo que compreenda uma política de ação afirmativa deve considerar, em primeiro lugar, as diferenças de experiência social entre os grupos-alvos a serem contemplados por ela. Propomos, então, a realização de dois processos seletivos, a serem regulamentados por editais específicos: um de caráter regular, contendo, porém, reserva de vagas para candidatos autodeclarados pretos e pardos e pessoas com deficiência; e outro direcionado exclusivamente para candidatos autodeclarados indígenas, em razão de suas trajetórias e formações escolares historicamente diferenciadas daquelas dos outros públicos de optantes. Em síntese, a proposta prevê a reserva, no mestrado e no doutorado, de até $20 \%$ das vagas oferecidas para os candidatos que se autodeclararem pretos e pardos, e de até $5 \%$ para pessoas com deficiência; além da criação de uma cota fixa de três vagas para optantes indígenas.

É fundamental ressaltar, ademais, que esta Comissão entende que uma política eficaz de ações afirmativas não se limita às adequações no processo seletivo de ingresso de candidatos. Ações anteriores e posteriores a essa etapa são necessárias, de forma a garantir uma adequada arregimentação e habilitação de candidatos (divulgação entre potenciais candidatos, cursos preparatórios e de extensão etc.), bem como o acompanhamento dos ingressantes (políticas de bolsas segundo critérios socioeconômicos, comissões de avaliação periódica e de apoio acadêmico e institucional etc.). Por conseguinte, as mudanças no processo seletivo exigem avaliação continuada de nossa Comissão, a partir de sua implementação e considerada essa premissa. Tais considerações se fazem presentes na proposta formulada.

Construída a proposta de reformulação do edital de seleção de ingresso na pós-graduação conforme as diretrizes acima expostas, o passo seguinte foi sua tramitação em diferentes instâncias administrativas da FFLCH e da USP. O pedido de reformulação/alteração do processo seletivo do PPGAS tramitou, foi discutido e aprovado com unanimidade dos votos na Comissão Coordenadora do Programa (CCP) em 14 de agosto de 2014; na Comissão de Pós-Graduação da FFLCH (CPG) em 15 de dezembro de 2014; e na Congregação da FFLCH em 25 de março de 2015, tendo seguido subsequentemente para a Câmara de Normas e Recursos do Conselho de Pós-Graduação da Universidade de São Paulo. 
Cabe ressaltar que endossaram o pedido pareceres jurídicos externos à Universidade de São Paulo, emitidos por membros do Ministério Público do estado de São Paulo, da Defensoria Pública do estado de São Paulo e da Organização das Nações Unidas. No âmbito da FFLCH, a Comissão de Pós-Graduação (CPG) e a Congregação aprovaram o pedido com base em pareceres circunstanciados e idôneos, emitidos por docentes indicados respectivamente pelo presidente (no caso da CPG) e pelo diretor (no caso da Congregação) da FFLCH.

No entanto, sem qualquer objeção ao seu teor, a Câmara de Normas e Recursos do Conselho de Pós-Graduação encaminhou o pedido para o gabinete da Reitoria solicitando-lhe "resposta institucional". Tal conduta contrapôs-se aos procedimentos regimentais previstos, segundo os quais compete à Câmara de Normas e Recursos do Conselho de Pós-Graduação deliberar sobre "os regulamentos e normas dos programas e suas eventuais alterações” (artigo 19, §I do Regimento de Pós-Graduação da USP), em conformidade com as diretrizes de autonomia e gestão atribuídas aos programas de pós-graduação desta Universidade previstas no Artigo 37 do referido Regimento. ${ }^{8}$ O pedido de reformulação/alteração das Normas e Regras de ingresso no PPGAS transcorreu nas instâncias para avaliação e votação da USP por 24 meses, permanecendo 7 deles sob a guarda da Reitoria. Contudo, o processo foi arquivado em 21 de dezembro de 2015: "até nova provocação".

Ao tomarmos ciência dessa decisão, manifestamos formalmente, enquanto Comissão, nossa indignação com relação ao arquivamento do pedido. Em primeiro lugar, não foi apresentada qualquer justificativa para o arquivamento; em segundo lugar, o envio da proposta pela Câmara de Normas e Recursos para o gabinete do reitor fere o regimento e desconsidera os esforços da comunidade uspiana e dessa Comissão em particular de participar dos processos de construção de políticas acadêmicas; em terceiro lugar, trata-se de um esforço intransigente de certas instâncias em manter uma política anticotas, ignorando os debates e demandas por ações afirmativas realizados por instituições da própria universidade, notadamente da unidade a que essa proposta se refere (os colegiados da FFLCH reiteradamente têm declarado em público serem favoráveis ao sistema de cotas e, inclusive, têm mencionado nossa proposta como política de ação afirmativa e aumento da diversidade por parte da Universidade de São Paulo); em quarto lugar, esse arquivamento também ignora as mobilizações e debates produzidos pela sociedade civil e marcadamente os movimentos sociais, que têm pautado o debate pela democratização do ensino superior desde o processo de redemocratização do país; por fim, a contínua omissão da universidade em implementar cotas e ações

\footnotetext{
${ }^{8}$ Que afirma: “Cabe a cada Programa de Pós-Graduação elaborar seu regulamento e normas, que deverão ser aprovados pela CPG responsável pelo Programa, com as particularidades de sua área, respeitando o estabelecido pela CPG e CoPGr em suas decisões, normas, Regimentos e Regulamentos". Disponível em: <http://www.leginf.usp.br/?resolucao=resolucao-no-6542-de-18-de-abril-de-2013>. Acesso em: 1º fev. 2017.
} 
afirmativas tem caráter atestadamente inconstitucional, diante da Lei de Cotas, do parecer do STF e da Portaria Normativa aprovada pela presidenta Dilma Rousseff. Esse arquivamento, em suma, é sintomático da recusa da universidade em atualizar suas instâncias e processos decisórios para formas mais democráticas, alinhadas às diretrizes e leis da Constituição Federal de 1988 e, em particular, de renunciar ao caráter de formação e reprodução de elites, que marcou sua criação, para se tornar efetivamente uma instituição de formação de profissionais e produção de conhecimentos plurais que constituem a sociedade brasileira.

Conforme exposto anteriormente, a ideia de se criar uma proposta de cotas para o PPGAS/USP nasceu no contexto da greve de 2013. A redação dessa proposta pautou-se por um estudo exaustivo dos regimentos da USP, bem como das políticas de cotas já implementadas em outras universidades brasileiras, de modo a ser juridicamente coerente e institucionalmente viável. Essa elaboração também é tributária de discussões que foram planejadas, ainda nesse momento, por meio da realização de diversos eventos que contaram, inclusive, com a participação de convidados de outras instituições e que expuseram as especificidades, demandas e potenciais dos segmentos sociais abarcados pela proposta. Uma vez elaborada a proposta, foram solicitados pareceres jurídicos externos acima referidos. Somente, então, iniciaram-se os trâmites institucionais na Universidade para avaliação da proposta, que, por sua vez, suscitaram novas discussões no interior desses fóruns, para as quais contribuíram membros da CPAA, valendo-se do conhecimento acumulado durante todo esse processo de elaboração e tramitação.

Paralelamente, todo esse movimento ultrapassou as esferas institucionais da FFLCH, despertando interesse de outras unidades da USP. Isto demonstra o quanto a Universidade está atrasada em acolher o debate, posto que antes da tramitação da nossa proposta, uma política de cotas jamais havia sido institucionalmente discutida e votada na USP. ${ }^{9}$ O grande e geral interesse por parte da comunidade uspiana por essa questão se exprimiu, de maneira inequívoca, nos numerosos eventos para os quais membros desta CPAA foram convidados a apresentar sua proposta, bem como os caminhos percorridos na sua elaboração, entre estudantes e professores de diferentes unidades da USP, tais como o Instituto de Ciências Biológicas, Instituto de Física, Museu de Arqueologia e Etnologia, Instituto de Psicologia, Faculdade de Educação, Escola Politécnica e Faculdade de Saúde Pública.

\footnotetext{
${ }^{9}$ Considerada uma "medida de inclusão", a área de concentração em Direitos Humanos do Programa de Pós-Graduação em Direito da Universidade de São Paulo prevê o direcionamento de vagas, por um sistema de ponderação, para pessoas: i. pertencentes a etnias negra e indígena; ii. portadoras de deficiência física grave; iii. que estejam em situação de hipossuficiência socioeconômica. Contudo, desconhecemos que tenha sido apresentada qualquer proposta de ações afirmativas ou tramitado qualquer documento no âmbito da Universidade que transformasse a iniciativa dessa área de concentração em uma política geral e institucional do Programa de Pós-Graduação em Direito da USP.
} 
Essa diversidade de áreas é indicativa de que a busca pela ampliação da diversidade dos quadros discentes - e os efeitos esperados dessa diversidade na formação de profissionais e pesquisadores e na produção de conhecimento - não se restringe à antropologia ou às chamadas ciências humanas.

Além disso, nossa proposta inspirou outros programas de pós-graduação em antropologia social a discutir e formular suas próprias políticas de ações afirmativas. Tais políticas avançaram com maior celeridade e foram implementadas nos programas de pós-graduação em antropologia da Unicamp, UFG, UFRGS e serão implementadas em breve na UFSCar.

Ou seja, o atual esforço da Comissão iniciou-se em 2013, mas responde aos anseios e demandas políticas que nos antecedem ao menos em duas décadas e corresponde a uma série de trabalhos, debates e dedicação que não se encerram nos longos 31 meses decorridos entre o início da tramitação oficial da proposta e a comunicação de seu arquivamento. Os trabalhos relatados de pesquisa, fundamentação, debate e publicização; os efeitos externos decorridos do trabalho da comissão em outras unidades e universidades e a sua repercussão positiva atestam que a proposta de cotas do PPGAS/USP não é um sonho utópico de um pequeno grupo de pessoas, mas o produto amadurecido de um esforço de longa duração, que busca solucionar uma inadequação da universidade à sua função social.

Um esforço que, a despeito dos entraves institucionais ora enfrentados, continua a amadurecer. No momento da elaboração da nossa proposta inicial, a discussão de reservas de vagas ou criação de vagas para atender outras demandas, como as de quilombolas e pessoas trans (que se identificam como homens ou mulheres trans, travestis, pessoas não binárias ${ }^{10}$ ainda era incipiente, posto que tais demandas ainda estavam se consolidando por parte desses movimentos. Felizmente este quadro vem mudando e nossa atenção para essas especificidades segue sendo uma meta para a implementação futura e paulatina de ações afirmativas no PPGAS/USP.

Para concluir, consideramos a implementação de ações afirmativas no PPGAS/USP um passo indispensável ao avanço da produção e circulação de conhecimento. Tal iniciativa responde a uma exigência colocada à antropologia como campo disciplinar no cenário nacional e internacional e, ao mesmo tempo, corresponde aos anseios de inclusão social no âmbito da Universidade de São Paulo. E é como fruto desse intenso trabalho de ideias e ações compartilhadas que conquistamos em nosso programa de pós-graduação a efetiva implementação de cotas para o edital de seleção de 2017, recebendo já em 2018 com entusiasmo estudantes cotistas como discentes no PPGAS, desenvolvendo suas pesquisas e contribuindo com múltiplos olhares e experiências na produção de um conhecimento mais coletivo e diverso.

\footnotetext{
${ }^{10}$ Pessoas não binárias são aquelas cuja identidade de gênero não se assenta nas categorias "homem" ou "mulher", assumindo outras formas ou sendo fluida.
} 


\section{Referências bibliográficas}

BRASIL. Lei no 12.711, de 29 de agosto de 2012. Dispõe sobre o ingresso nas universidades federais e nas instituições federais de ensino técnico de nível médio e dá outras providências. Disponível em: <http://www.planalto.gov. br/ccivil_03/_ato2011-2014/2012/Lei/L12711.htm>. Acesso em: 31 jan. 2017.

BRASIL. Lei no 13.409, de 28 de dezembro de 2016. Dispõe sobre a reserva de vagas para pessoas com deficiência nos cursos técnicos, de nível médio e superior das instituições federais de ensino. Disponível online em: <http:// www.planalto.gov.br/ccivil_03/_Ato2015-2018/2016/Lei/L13409.htm\#art1>. Acesso em: 31 jan. 2017.

Portaria normativa $\mathrm{n}^{\circ} 13$, de 11 de maio de 2016. Dispõe sobre a indução de Ações Afirmativas na Pós-Graduação, e dá outras providências. Disponível em: <http:/www.capes.gov.br/images/stories/download/legislacao/12052016-PORTARIA-NORMATIVA-13-DE-11-DE-MAIO-DE-2016-E-PORTARIA-N-396-DE-10-DE-MAIO-DE-2016.pdf>. Acesso em: 31 jan. 2017.

CARVALHO, José Jorge. A politica de cotas no ensino superior e na pesquisa. Brasília: CNPQ/Universidade de Brasília/Ministério da Educação (MEC), 2016.

GUIMARÃES, Antonio Sérgio A.; RIOS, Flavia M. Cotas nas universidades públicas. Afro-Ásia, n. 50, 2014, p. 251-6.

SANTOS, Jocélio Teles dos. O impacto das cotas nas universidades brasileiras (2004 2012). Salvador: Centro de Estudos Afro-Orientais da UFBA, 2013. 278p.

UFAM. Pró-Reitoria de Pesquisa e Pós-Graduação. Programa de Pós-Graduação em Antropologia Social. Edital no 026/2011-Popesp/Ufam. Edital no 050/2016-Propesp/Ufam. Disponível em: <http://ppgas.ufam.edu.br/images/Processo_seletivo/Edital_n.050-2016-PROPESP-UFAM.pdf>. Acesso em: $1^{\circ}$ fev. 2017.

UFPA. Programa de Pós-Graduação em Antropologia. Edital no 001/2012. Disponível em: <http://www.ascom.ufpa.br/links/editalan.pdf>. Acesso em: $1^{\circ}$ fev. 2017.

UFRJ. Programa de Pós-Graduação em Antropologia Social. Resolução no 6/2012. Edital no 37/2013. Edital no 39/2013. Disponível em: <http://www. ppgasmn-ufrj.com/uploads/2/7/2/8/27281669/resolucao_6_2012_acao_ afirmativa_1_.pdf>. Acesso em: $1^{\circ}$ fev. 2017.

UFSC. Programa de Pós-Graduação em Antropologia Social. Edital no 6/2012/ PPGAS. Disponível em: <http://ppgas.posgrad.ufsc.br/files/2013/04/ Edital-6-PPGAS-2013-Sele\%C3\%A7\%C3\%A3o-Mestrado-2014-A\%C3\%A7\%C3\%B5es-Afirmativas.pdf >. Acesso em: 10 fev. 2017. 
UNB. Programa de Pós-Graduação em Antropologia Social. Edital no 003/2014. Disponível em: <http://dan.unb.br/images/pdf/ppgas-selecao/2014/Edital_PPG_Antropologia_Mestrado2015.pdf>. Acesso em $1^{\circ} \mathrm{fev}$. 2017. Edital $n^{\circ}$ 04/2014. Disponível em: <http://dan.unb.br/images/pdf/ppgas-selecao/2014/EditalPPGAntropologiaDoutorado-no-Brasil-12015.pdf>. Acesso em $1^{\circ}$ fev. 2017. Edital no 005/2014. Disponível em: <http://dan.unb.br/ images/pdf/ppgas-selecao/2014/EditalPPGMestradoIndigenas12015.pdf>. Acesso em: $1^{\circ}$ fev. 2017. Edital no 06/2014. Disponível em: <http://dan.unb. br/images/pdf/ppgas-selecao/2014/EditalPPGDoutoradoIndigena12015. pdf $>$. Acesso em $1^{\circ}$ fev. 2017.

USP. Curso de Pós-Graduação da Faculdade de Direito da Universidade de São Paulo. Edital Fd/Pós/Sel. no 01/2016. Universidade de São Paulo, São Paulo, 2016. Disponível em: <http://www.direito.usp.br/pos/arquivos/folder_ medidas_2016.pdf>. Acesso em $1^{\circ}$ fev. 2017.

\section{Autoras Ana Claudia Marques}

Professora Doutora do Departamento de Antropologia da Universidade de São Paulo - anaclaudiadrm@gmail.com.

\section{Ana Letícia de Fiori}

Doutoranda PPGAS/USP - morgotia@gmail.com.

\section{Cibele Barbalho Assênsio}

Mestra em Antropologia Social pela USP - cibele.assensio@ gmail.com.

\section{Fabiana de Andrade}

Doutoranda PPGAS/USP - fabiandrade79@yahoo.com.br.

\section{Jacqueline Moraes Teixeira}

Doutoranda PPGAS/USP - jamoteka@gmail.com.

\section{Letizia Patriarca}

Doutoranda PPGAS/USP - patr.letizia@gmail.com.

Talita Lazarin Dal' Bó

Doutoranda PPGAS/USP - talita.lazarin@gmail.com. 